8. Пасечникова Н. В. Высокочастотная электросварка тканей заднего отдела глазного яблока (модифицированный генератор ЕК-300M1) с применением оригинального моно- и биполярного инструментария / Пасечникова Н. В., Уманец Н. Н., Артемов А. В. [и др.]. Офтальмол. Журн. - 2012. - № 2. - С.45-49.

9. Уманец Н. Н. Влияние высокочастотной элетросварки биологических тканей (модифицированный гене- ратор ЭЕ-300М1) на длительность кровотечения из магистральных сосудов сетчатки при моделировании внутриглазного кровотечения у кроликов по сравнению с диатермокоагуляцией / Уманец Н. Н. Офтальм. Журн. - 2012. - № 4. - С.88-91.

Поступила 08.08.2012

Рецензент проф., д. М. н. Э. В. Мальцев

\title{
STRUCTURAL CHANGES OF THE VESSELS OF THE MEDULLAR RADIATION OF THE RETINA AND CHORIORETINAL COMPLEX IN THE RABBIT UNDER THE EFFECT OF HIGH FREQUENCY ELECTROWELDING OF THE BIOLOGICAL TISSUES IN MODELING INTRAOCULAR HEMOR- RHAGE \\ Pasechnikova N. V., Vit V.V., Naumenko V. A., Umanets N. N. Odessa, Ukraine
}

It was established on the model of the intraocular hemorrhage in rabbits that the application of high frequency electrowelding of the biological tissues (modified generator EK-300M1) with parameters of the electric current: voltage- $18-20 \mathrm{~W}$, strength - up to $0.1 \mathrm{~A}$, exposition $-1-2 \mathrm{~s}$, frequency $-66 \mathrm{kHz}$ causes coagulation of the main vessels of the retina and obliteration of their lumen with phenomena of coagulation necrosis of the retina in the area under the effect; in this case its degree is significantly less than in diathermocoagulation with the parameters: voltage $-10 \mathrm{~W}$, frequency $-365 \mathrm{kHz}$, exposition $-1-2 \mathrm{~s}$.

УДК 617.741-004.1-092.9-085-036.8

\section{ЭФФЕКТИВНОСТЬ АНТИКАТАРАКТОГЕННОГО ДЕЙСТВИЯ КАРОТИНОИДОВ (ЛЮТЕИНА И ЗЕАКСАНТИНА) ПРИ РАЗВИТИИ ЭКСПЕРИМЕНТАЛЬНОЙ КАТАРАКТЫ}

\author{
Н. Ф. Леус, проф., Будайа Низар, аспирант, Т. В. Пархоменко, ст. лаборант \\ ГУ «Институт глазных болезней и тканевой терапии им В. П. Филатова НАМН Украины»
}

Введение. Катаракта является главной причиной слепоты и слабовидения в мире. По данным ряда исследователей, число незрячих вследствие этого заболевания составляет более 20 млн., а к 2020 году прогнозируется еще большее их увеличение [1, $3,20]$.

Количество таких больных, по всей вероятности, будет расти в связи с увеличением продолжительности жизни населения. А в результате повышения уровня общего фона радиации на земном шаре можно ожидать не только увеличения частоты возникновения катаракты, но и развития этого заболевания у лиц более молодого возраста [6, 7].

Имеются данные о роли нарушений физиологического равновесия между процессами перекисного окисления липидов и активностью антиоксидантной системы в патогенезе возрастной катаракты $[9,12,17,18]$.

Благодаря многочисленным исследованиям получены убедительные доказательства того, что важнейшим звеном в патогенезе катаракты является дисбаланс процессов свободно-радикального окисления (белков, липидов и др. компонентов) и потенциала антирадикальной системы («гашение» радикалов) экзогенного и эндогенного характера. В результате этого дисбаланса в организме резко повышается концентрация пероксидов и снижается уровень функциональных групп белков (карбоксильных, тиоловых и др.) $[4,7,18,20]$.

Несмотря на значительные усилия, направленные в течение последних десятилетий на изучение патогенеза возрастной катаракты и разработку новых средств ее консервативного лечения и профилактики, распространение этого заболевания продолжает возрастать. В этой связи актуальным остается поиск новых и усовершенствование существующих способов медикаментозной профилактики и лечения катаракты на ранней стадии ее развития $[2,10,20]$.

В последнее время большой интерес у медиков вызывают препараты, которые не являются чужеродными для организма человека. Так, в частности, особый интерес проявляется к каротиноидам - лютеину и зеаксантину - оба каротиноида поступают с пищей в кровяное русло и в конечном итоге накапливаются в тканях глаза [10, 15, 22, 23, 26, 29, 30].

(ㄱ Н. Ф. Леус, Будайа Низар, Т. В. Пархоменко, 2012 
Из всех форм каротиноидов к органу зрения прямое отношение имеют лютеин и зеаксантин, биологическая роль которых изучалась, главным образом, в сетчатой оболочке $[11,28]$.

В то же время в последние годы указанные каротиноиды обнаружены в хрусталике [30]. Принимая во внимание их высокий антиоксидантный потенциал, а также роль оксидативного стресса в патогенезе возрастной катаракты, представляется актуальным изучение роли лютеина и зеаксантина в патогенезе возрастной катаракты [28,21].

Прямых исследований в этом направлении до настоящего времени не проводилось, однако результаты ряда клинических наблюдений можно рассматривать как предпосылки того, что лютеин и зеаксантин могут способствовать снижению риска возникновения возрастной катаракты. [14, 15, 16, 19, 20, 22, 25, 26, 29].

Нами в предыдущей работе было выявлено стабилизирующее действие зеаксантина и лютеина на биофизические свойства хрусталиковых компонентов при воздействии катарактогенных факторов.

Цель работы: изучить возможность каротиноидов (лютеина и зеаксантина) замедлять развитие экспериментальной катаракты.

МАТЕРИАЛ И МЕТОДЫ ИССЛЕДОВАНИЯ. Экспериментальные исследования проводились на 24 кроликах (массой 2,5-3,2 кг).

При проведении эксперимента соблюдались все рекомендации относительно исследований на животных.

Моделирование световой катаракты осуществляли в течение 40 недель у кроликов породы шиншилла. Опытные группы животных подвергали воздействию облучения светом дуговой ртутной лампы типа ДРФ - 1000 (1000 ВТ) высокой интенсивности в спектральном диапазоне от 350 до 1150 нм ежедневно в режиме светового дня в течение 9 часов [5].

Животные были разделены на две группы: группа «свет» -12 кроликов (24 глаза) и группа «свет+каротиноиды» - 12 кроликов (24 глаза).

На протяжении эксперимента состояние хрусталиков оценивали биомикроскопически с использованием щелевой лампы фирмы «Карл Цейс». Зрачки предварительно расширялись инстилляциями 1-2 капель $1 \%$ раствора атропина. Осмотр проводили перед началом и каждые две недели до окончания эксперимента.

При оценке изменений в хрусталиках экспериментальных животных учитывалось пять стадий:

0 степень - прозрачный хрусталик, отсутствие субкапсулярных вакуолей, задний шов узкий с четкими границами.

1 стадия - наличие единичных или множественных мелких заднекапсулярных вакуолей, отсутствие изменений в других зонах хрусталика.

2 степень - наличие множественных мелких вакуолей преимущественно в заднекапсулярных слоях хрусталика, а также единичных мелких вакуолей в других зонах хрусталика.

3 степень - наличие множественных разнокалиберных вакуолей в заднекапсулярных слоях, появление единичных крупных вакуолей в других слоях хрусталика, наличие или отсутствие мелких точечных помутнений в области заднего шва.

4 степень - наличие множественных разнокалиберных вакуолей как в субкапсулярных слоях, так и в других зонах хрусталика, наличие мелких точечных помутнений в области заднего шва, слабое диффузное помутнение ядра хрусталика.

5 степень - наличие крупных сливных вакуолей в субкапсулярных и множественных разнокалиберных вакуолей в других зонах хрусталика, сливные мелкоточечные помутнения в области заднего шва, интенсивное помутнение ядра хрусталика.

Полученные при экспериментальных исследованиях количественные данные были подвергнуты статистическому анализу [8].

РЕЗУЛЬТАТЫ И ИХ ОБСУЖДЕНИЕ. ДаНные, полученные при изучении влияния каротиноидов (лютеина и зеаксантина) на развитие патологических изменений в хрусталиках кроликов при моделировании световой катаракты представлены в таблицах 1-2.

Таблица 1

Влияние каротиноидов (лютеина и зеаксантина) на развитие патологических изменений в хрусталиках кроликов при моделировании световой катаракты

\begin{tabular}{|c|c|c|c|c|c|}
\hline \multirow{3}{*}{$\begin{array}{l}\text { Сроки на- } \\
\text { блюдения }\end{array}$} & \multirow{3}{*}{$\begin{array}{c}\text { Степень } \\
\text { патоло- } \\
\text { гических } \\
\text { изменений }\end{array}$} & \multicolumn{4}{|c|}{ Условия эксперимента } \\
\hline & & \multicolumn{2}{|c|}{ Свет } & \multicolumn{2}{|c|}{$\begin{array}{c}\text { Свет + кароти- } \\
\text { ноиды }\end{array}$} \\
\hline & & $\begin{array}{l}\text { Количе- } \\
\text { ство глаз }\end{array}$ & $\%$ & $\begin{array}{l}\text { Количе- } \\
\text { ство глаз }\end{array}$ & $\%$ \\
\hline \multirow{2}{*}{$\begin{array}{c}\text { До на- } \\
\text { чала } \\
\text { экспери- } \\
\text { мента }\end{array}$} & 0 & 24 & 100,0 & 24 & 100,0 \\
\hline & Всего & 24 & 100,0 & 24 & 100,0 \\
\hline \multirow{7}{*}{10 недель } & 0 & 16 & 66,6 & 21 & 87,5 \\
\hline & 1 & 7 & 29,2 & 3 & 12,5 \\
\hline & 2 & 1 & 4,2 & - & - \\
\hline & 3 & - & - & - & - \\
\hline & 4 & - & - & - & - \\
\hline & 5 & - & - & - & - \\
\hline & Всего & 24 & 100,0 & 24 & 100,0 \\
\hline \multirow{7}{*}{20 недель } & 0 & 8 & 33,3 & 14 & 58,4 \\
\hline & 1 & 11 & 45,8 & 8 & 33,3 \\
\hline & 2 & 4 & 16,7 & 2 & 8,3 \\
\hline & 3 & 1 & 4,2 & - & - \\
\hline & 4 & - & - & - & - \\
\hline & 5 & - & - & - & - \\
\hline & Всего & 24 & 100,0 & 24 & 100,0 \\
\hline \multirow{7}{*}{30 недель } & 0 & 2 & 8,3 & 5 & 20,8 \\
\hline & 1 & 9 & 37,5 & 12 & 50,0 \\
\hline & 2 & 8 & 33,3 & 7 & 29,2 \\
\hline & 3 & 4 & 16,7 & - & - \\
\hline & 4 & 1 & 4,2 & - & - \\
\hline & 5 & - & - & - & - \\
\hline & Всего & 24 & 100,0 & 24 & 100,0 \\
\hline \multirow{7}{*}{40 недель } & 0 & - & - & - & - \\
\hline & 1 & 2 & 8,3 & 7 & 29,2 \\
\hline & 2 & 7 & 29,2 & 11 & 45,8 \\
\hline & 3 & 7 & 29,2 & 5 & 20,8 \\
\hline & 4 & 5 & 20,8 & 1 & 4,2 \\
\hline & 5 & 3 & 12,5 & - & - \\
\hline & Всего & 24 & 100,0 & 24 & 100,0 \\
\hline
\end{tabular}

Примечание. \% - по отношению к общему количеству глаз в каждой группе в зависимости от срока наблюдения. 


\section{Таблица 2}

Ранговая оценка развития патологических изменений в хрусталиках кроликов при световой катаракте и под влиянием каротиноидов

\begin{tabular}{|c|c|c|c|}
\hline \multirow{2}{*}{$\begin{array}{l}\text { Сроки на- } \\
\text { блюдения }\end{array}$} & \multirow{2}{*}{$\begin{array}{c}\text { Статистические } \\
\text { показатели }\end{array}$} & \multicolumn{2}{|c|}{ Условия эксперимента } \\
\hline & & Свет & $\begin{array}{c}\text { Свет + кароти- } \\
\text { ноиды }\end{array}$ \\
\hline \multirow{2}{*}{$\begin{array}{c}\text { Начало } \\
\text { экспери- } \\
\text { мента }\end{array}$} & \multirow{2}{*}{$\begin{array}{c}\mathrm{n} \\
\text { Средний ранг } \\
\text { Сумма рангов } \\
\mathrm{U} \\
\mathrm{W} \\
\mathrm{p}\end{array}$} & $\begin{array}{c}24 \\
24,50 \\
588,00\end{array}$ & $\begin{array}{c}24 \\
24,50 \\
588,00\end{array}$ \\
\hline & & \multicolumn{2}{|c|}{$\begin{array}{c}288,00 \\
588,00 \\
1,000\end{array}$} \\
\hline \multirow{2}{*}{10 недель } & \multirow{2}{*}{$\begin{array}{c}\mathrm{n} \\
\text { Средний ранг } \\
\text { Сумма рангов } \\
\mathrm{U} \\
\mathrm{W} \\
\mathrm{p} \\
\end{array}$} & $\begin{array}{c}24 \\
27,06 \\
649,50\end{array}$ & $\begin{array}{c}24 \\
21,94 \\
526,50\end{array}$ \\
\hline & & \multicolumn{2}{|c|}{$\begin{array}{c}226,50 \\
526,50 \\
0,082\end{array}$} \\
\hline \multirow{2}{*}{20 недель } & \multirow{2}{*}{$\begin{array}{c}\mathrm{n} \\
\text { Средний ранг } \\
\text { Сумма рангов } \\
\mathrm{U} \\
\mathrm{W} \\
\mathrm{p}\end{array}$} & $\begin{array}{c}24 \\
28,30 \\
679,50\end{array}$ & $\begin{array}{c}24 \\
20,69 \\
496,50\end{array}$ \\
\hline & & \multicolumn{2}{|c|}{$\begin{array}{c}196,50 \\
496,50 \\
0,039\end{array}$} \\
\hline \multirow{2}{*}{30 недель } & \multirow{2}{*}{$\begin{array}{c}\mathrm{n} \\
\text { Средний ранг } \\
\text { Сумма рангов } \\
\mathrm{U} \\
\mathrm{W} \\
\mathrm{p}\end{array}$} & $\begin{array}{c}24 \\
28,67 \\
688,00 \\
\end{array}$ & $\begin{array}{c}24 \\
20,33 \\
488,00 \\
\end{array}$ \\
\hline & & \multicolumn{2}{|c|}{$\begin{array}{c}188,00 \\
488,00 \\
0,028 \\
\end{array}$} \\
\hline \multirow{2}{*}{40 недель } & \multirow{2}{*}{$\begin{array}{c}\mathrm{n} \\
\text { Средний ранг } \\
\text { Сумма рангов } \\
\mathrm{U} \\
\mathrm{W} \\
\mathrm{p}\end{array}$} & $\begin{array}{c}24 \\
30,31 \\
727,50 \\
\end{array}$ & $\begin{array}{c}24 \\
18,69 \\
448,50 \\
\end{array}$ \\
\hline & & \multicolumn{2}{|c|}{$\begin{array}{c}148,50 \\
448,50 \\
0,003 \\
\end{array}$} \\
\hline
\end{tabular}

Примечание. $\mathrm{p}$ - достоверность различий между группами по ранговому критерию Манна-Уитни.

На 10 неделе моделирования катаракты 16 хрусталиков $(66,6 \%)$ в группе «свет» и 21 хрусталик $(87,5 \%)$ в группе «свет+каротиноиды» оставались прозрачными. В 7 хрусталиках $(29,2 \%)$ в группе «свет» и в 3 хрусталиках $(12,5 \%)$ в группе «свет+каротиноиды» наблюдалось появление единичных или множественных субкапсулярных вакуолей при отсутствии их в других слоях хрусталика. В одном хрусталике $(4,2 \%)$ в группе «свет» вакуоли в заднекапсулярной зоне носили разнокалиберный характер.

На 20 неделе эксперимента 8 хрусталиков $(33,3 \%)$ в группе «свет» и 14 хрусталиков $(58,4 \%)$ в группе «свет+каротиноиды» оставались прозрачными. В 11 хрусталиках $(45,8 \%)$ в группе «свет» и 8 хрусталиках $(33,3 \%)$ в группе «свет+каротиноиды» наблюдалось появление единичных или множественных субкапсулярных вакуолей при отсутствии их в других слоях хрусталика. В 4 хрусталиках $(16,7 \%)$ в группе «свет» и 2 хрусталиках $(8,3 \%)$ в группе «свет+каротиноиды» вакуоли в заднекапсулярной зоне носили разнокалиберный характер. III степень помутнения наблюдалась в одном хрусталике $(4,2 \%)$ в группе «свет».

На 30 неделе эксперимента прозрачными оставались 2 хрусталика $(8,3 \%)$ в группе «свет» и 5 хрусталиков $(20,8 \%)$ в группе «свет+каротиноиды». В 9 хрусталиках $(37,5 \%)$ в группе «свет» и 12 хрусталиках $(50,0 \%)$ в группе «свет+каротиноиды» наблюдалось появление единичных или множественных субкапсулярных вакуолей при отсутствии их в других слоях хрусталика. В 8 хрусталиках $(33,3 \%)$ в группе «свет» и 7 хрусталиках $(29,2 \%)$ в группе «свет+каротиноиды» вакуоли в заднекапсулярной зоне носили разнокалиберный характер. III и IV степени помутнения хрусталика отмечены в 4 хрусталиках $(16,7 \%)$ и 1 хрусталике $(4,2 \%)$ в группе «свет» соответственно.

На 40 неделе эксперимента в 2 хрусталиках $(8,3 \%)$ в группе «свет» и в 7 хрусталиках $(29,2 \%)$ в группе «свет+каротиноиды» отмечались единичные субкапсулярные вакуоли. В 7 хрусталиках $(29,2 \%)$ в группе «свет» и 11 хрусталиках $(45,8 \%)$ в группе «свет+каротиноиды» помутнения ограничивались заднекапсулярной зоной. В 7 хрусталиках $(29,2 \%)$ в группе «свет» и 5 хрусталиках $(20,8 \%)$ в группе «свет+каротиноиды» единичные или множественные мелкие вакуоли распространялись и в другие слои хрусталика. В 5 хрусталиках $(20,8 \%)$ в группе «свет» и 1 хрусталике $(4,2 \%)$ в группе «свет+каротиноиды» изменения были более выражены, захватывали также и область заднего шва. В 3 хрусталиках $(12,5 \%)$ в группе «свет» отмечалась $\mathrm{V}$ степень помутнения.

Результаты, полученные в настоящей работе, дополняют наше представление о возможном профилактическом действии лютеина и зеаксантина при развитии возрастной катаракты, что также подтверждается нашими предыдущими исследованиями о влиянии каротиноидов на устойчивость компонентов хрусталика в опытах in vitro [3].

Необходимо отметить, что наши результаты в сопоставлении с данными работ о превентивном действии каротиноидов на хрусталик при развитии экспериментального диабета убедительно доказывают роль лютеина и зеаксантина в стабилизации хрусталика при воздействии катарактогенных факторов [12, 13].

\section{ЗАКЛЮЧЕНИЕ}

В условиях моделирования световой катаракты применение каротиноидных препаратов (лютеина и зеаксантина) замедляет развитие первичных помутнений в хрусталиках экспериментальных животных уже в ранние сроки наблюдения. Так у животных, получавших световое облучение, через 
10 недель воздействия первая и вторая степени патологических изменений в хрусталиках наблюдались в 29,2 \% и 4,2\% случаев соответственно, а при применении препаратов - только первая степень (12,5 \% случаев) от общего количества глаз в каждой группе.

Изученные каротиноиды существенно повышают устойчивость хрусталика к длительному водействию катарактогенного фактора. Если при световом воздействии количество глаз с первой и второй степенью патологических изменений было значительно меньше, чем при применении препаратов, то с третьей степенью количество таких случаев составляло $29,2 \%$ и 20,8 \%, четвертой - 20,8\%о и 4,2\%, соответственно. Следует также отметить наличие патологических изменений с пятой степенью патологических изменений в $12,5 \%$ хрусталиков животных при действии катарактогенного фактора и отсутствие изменений при применении каротиноидных препаратов (лютеина и зеаксантина). Таким образом, после 40-недельного светового воздействия хрусталики в группе животных, получавших каротиноиды, оставались в значительной степени менее подверженными световому воздействию по сравнению с группой животных, не получавших указанные препараты после светового воздействия.

\section{ЛИТЕРАТУРА}

1. Веселовская 3. Ф. Катаракта / 3. Ф. Веселовская, Н. Ф. Боброва, В. В. Вит. - Киев: Книга плюс, 2002. $208 \mathrm{c}$.

2. Гусева М. Р. «Лютеин-комплекс детский» в педиатрической практике при заболеваниях глаз / Гусева М. Р., Дубовская Л. А. Маркова Е. Ю. // Российская педиатрическая офтальмология. - 2007. - № 1. - С. 9-14.

3. Леус Н. Ф. Влияние каротиноидов на стабильность антиоксидантных ферментов и биофизические свойства хрусталиковых компонентов при воздействии световой энергии / Н. Ф. Леус, Будайа Низар, Пархоменко Т. В. // Офтальмол. журн. - 2012. - № 2. - С. 43-48.

4. Леус Н. Ф. Уровень свободных аминокислот в хрусталике и камерной влаге глаза при развитии экспериментальной катаракты / Н. Ф. Леус, Аслам Набиль, А. А. Путиенко // Офтальмол. журн. - 2007. - № 3. - С. 50-54.

5. Леус М. Ф., Метеліцина І. П., Дрожжіна Г. І. та ін. Способ моделювання променевої катаракти: Пат. 20178 Україна, ПМК G 09 В 23/28, № 4712831/SU; Заявл. 13.07.89; Опубл. 25.12.97; Бюл. «Пром. власн.» № 6. - ч. 2. - С. 576 .

6. Мальцев Э. В. Эпидемиология катаракт / Э. В. Мальцев, Н. А, багиров // Офтальмол. журн. - 2001. № 6. - С. 45-49.

7. Мальцев Э. В. Биологические особенности и заболевания хрусталика / Э. В. Мальцев, К. П. Павлюченко. - Одесса: Астропринт, 2002. - 447 с.

8. Наследов А. SPSS компьютерный анализ данных в психологии и социальных науках. // Спб.: Питер, 2005. $-416 \mathrm{c}$.

9. Полунин Г. С. Классификация катаракт и возможность их терапевтического лечения / Г. С. Полунин,
Е. Г. Полунина, Н. Л, Шеремет // Рефракционная хирургия и офтальмология. - 2003. - Т. 3, № 2. C. $37-42$.

10. Трофимова Н. Н., Зак П. П., Островский М. А. Функциональная роль каротиноидов желтого пятна сетчатки глаза // Сенсорные системы. - 2003. - Т. 17. № 3. - С. 198-208.

11. Шальк В. Лютеин и зеаксантин: два основных компонента для здоровья глаз / Шальк В. // Офтальмол. журн. - 2010. - № 1. - С. 108-110.

12. Agardh E. Effects of inhibition of glycation and oxidative stress on the development of cataract and retinal vessels abnormalities in diabetic rats / Agardh E., Hultberg B., Agardh C. // Curr. Eye Res. - 2000. - Vol. 21. - P. 543-549.

13. Arnal E. Lutein prevents cataract development and progression in diabetic rats / Arnal E., Miranda M., Almansa I. // Graefes Arch. Clin. Exp. Ophthalmol. - 2008. Vol. 3. - P. 325-328.

14. Berendschot T. T. Lens aging in relations to nutritional determinants and possible risk factors for age-related cataract / Berendschot T. T., Broekmans W. M. R. // Arch. Ophthalmol. - 2002. - Vol. 120. - P. 1732-1737.

15. Brown L. A prospective study of carotenoid intake and risk of cataract extraction in US men / Brown L., Rimm E. B., Seddon J. M. // Am. J. Clin. Nutr. - 1999. - Vol. 70. P. 517-524.

16. Chasan-Taber L. A prospective study of carotenoid and vitamin A intakes and risk of cataract extraction in US women / Chasan-Taber L., Willett W. C., Seddon J. M. // Am. J. Clin. Nutr. - 1999. - Vol. 70. - P. 509-516.

17. Delcourt C. Risk factors for cortical, nuclear, and posterior subcapsular cataracts / Delcourt C., Cristol J. P., Tessier F. // Am. J. Epidemiol. - 2000. - Vol. 151. — № 5. P. 497-504.

18. Donma O. Blood and lens lipid peroxidation and antioxidant status in normal individuals, senile and diabetic cataractous patients / Donma O., Yorulmaz E., Pekel H. // Curr. Eye Res. - 2002. - Vol. 25. - P. 9-16.

19. Fernandez M. M. Nutrition and the prevention of cataracts / Fernandez M. M., Afshari N. A. // Curr. Opin. Ophthalmol. - 2008. - Vol. 19. - № 1. - P. 66-70.

20. Gale C. R. Plasma antioxidant vitamins and carotenoids and age-related cataract / Gale C. R., Hall N. F., Phillips D. I. W. // Ophthalmol. - 2001. - Vol. 108. P. 1992-1998.

21. Gruseki W. I. Carotenoid orientation: role in membrane stabilization / Gruseki W. I. // Marcel Deker. - 2004. P. $123-128$

22. Lyle B. J. Serum carotenoids and tocopherols and incidence of age-related nuclear cataract / Lyle B. J., MaresPerlman J. A., Klein B. // Am. J. Clin. Nutr. - 1999. Vol. 69. - P. 272-277.

23. Mares J. A. Predictors of optical density of lutein and zeaxanthin in retinal of older women in the carotenoids in age-related eye disease study, an ancillary study of the women's health initiative / Mares J. A., LaRowe T. L., Snoddererly D. M. // Am. J. Clin. Nutr. - 2006. Vol. 84. - P. 1107-1122.

24. Mares J. A., Carotenoids and eye disease epidemiologic evidence In: Krinsky. N. I., Mayne S., editors. Carotenoids in health \& Disease. Marcel Dekker Inc: NY: 2003. Chapter 19.

25. Moeller S. M. Associations between age-related nuclear cataract and lutein and zeaxanthin in the diet and serum in 
the carothenoids in age-related eye disease study, an ancillary study of the women's health initiative / Moeller S. M. Voland R., Tinker L. // Arch. Ophthalmol. - 2008. - Vol. 126. - № 3. - P. 354-364.

26. Taylor A. Long-term intake of vitamins and carotinoids and odds of early age-related cortical and posterior subcapsular lens opacities / A. Taylor, P. Jackues, L. T. Chylack // Am. J. Clin. Nutr. - 2002. - V. 75. - P. 540-549.

27. Thomson L. R. Elevated retinal zeaxanthhin and prevention of light-induced photoreceptor cell death in quail / Thomson L. R., Toyoda Y., Langner A. // Invest. Ophthalmol. Vis. Sci. - 2002. - Vol. 43. - P. 3538-3549.

28. Trevithick-Sutton C. C. The retinal carotenoids zeaxanthin and lutein scavenge superoxide and hydroxylradicals: a chemiluminescence and ESR study / Trevithick-Sutton C. C., Foote C. S., Collins M. // Mol. Vis. - 2006. Vol. 12. - P. 1127-1135.

29. Vu H. T. V. Lutein and zeaxanthin and risk of cataract: the Melbourne visual impairment project / Vu H. T. V., Robman L., Hodge A. // Invest. Ophthalmol. Vis. Sci. 2006. - Vol. 47. - P. 3783-3786.

30. Yeum K-J. Measurement of carotenoids, retinoids, and tocopherols in human lenses / Yeum K-J., Taylor A., Tang G. // Invest. Ophthalmol. Vis. Sci. - 1995. - Vol. 36. P. 2756-2761.

Поступила 06.08.2012 Рецензент д. мед. н. С. К. Дмитриев

УДК 617.735-002-02:616.379-008.64-092.9-091.8

\title{
СОСТОЯНИЕ СЕТЧАТОЙ И СОСУДИСТОЙ ОБОЛОЧЕК ГЛАЗА КРОЛИКА С САХАРНЫМ ДИАБЕТОМ, МОДЕЛИРОВАННЫМ ДИТИЗОНОМ. СООБЩЕНИЕ 4. СРАВНИТЕЛЬНОЕ МОРФОЛОГИЧЕСКОЕ СОПОСТАВЛЕНИЕ ФЕНОМЕНА НЕЙРОДЕГЕНЕРАЦИИ ПРИ ДИТИЗОНОВОМ И СТРЕПТОЗОТОЦИНОВОМ ДИАБЕТЕ
}

\author{
Э. В. Мальцев, проф., А. В. Зборовская, К. М. Н., А. Э. Дорохова, врач \\ ГУ «Институт глазных болезней и тканевой терапии НАМН Украины»
}

Ключевые слова: диабетическая ретинопатия, сетчатая оболочка, сосудистая оболочка, дитизоновый диабет, стрептозотоциновый диабет, нейродегенерация, гистологические изменения

В более ранних публикациях нами [3, 4] было показано, что при дитизоновой модели сахарного диабета (СД) такое его проявление как диабетическая ретинопатия (ДР) вообще и нейродегенерация при ней, в частности, носят ярко выраженный характер и развиваются всего за три-четыре месяца. В связи с этим возникает вопрос о том, как соотносятся нейродегенеративные изменения сетчатки при названной модели СД у кролика с аналогичными изменениями при других моделях данного заболевания в сопоставимых сроках наблюдения. Учитывая то обстоятельство, что таких моделей ДР известно достаточно $[9,14,15,16,20]$, мы полагаем рациональным избрать для сравнительного исследования те из них, которые наиболее распространены. Нет сомнений, что экспериментальная ДР при СД, вызываемом стрептозотоцином у крыс и мышей, относится как раз именно к таким моделям $[1,5,8,13,17,18,19]$.

Поэтому целью настоящего сообщения явилось сравнительное гистологическое сопоставление нейродегенеративных изменений сетчатой оболочки глаз нескольких видов лабораторных животных (кроликов, крыс и мышей) с воспроизведенным у них по известным методикам сахарным диабетом.

МАЕТРИАЛ И МЕТОДЫ. Вся необходимая информация о методике воспроизведения дитизонового СД у кроликов приведена в нашем более раннем сообщении [3].
Что же касается крыс и мышей, то нами были использованы препараты научного архива лаборатории патологической анатомии и электронноой микроскопии ГУ «Институт глазных болезней и тканевой терапии им В. П. Филатова НАМН Украины». При этом следует иметь в виду, что и у крыс линии Вистар, и у мышей линии СВА/C57B1хK/F1 СД моделировали с помощью стрептозотоцина. Однако у мышей индуцировали низкодозовый стрептозотоциновый диабет путем внутрибрюшинного введения цитостатика в дозе 40 мг/кг массы тела ежедневно на протяжении 5 суток. Этим путем достигалась абсолютная инсулиновая недостаточность, соответствующая инсулинзависимому типу сахарного диабета аутоиммунного генеза у человека [6]. Относительную инсулиновую недостаточность создавали с помощью модели неонатального стрептозотоцинового диабета [7]. Для этого 2-недельным крысятам вводился внутрибрюшинно стрептозотоцин в дозе 100 мг/кг массы тела. Эвтаназию животных производили под хлороформенным наркозом: мышей через 2 и 6 месяцев от начала эксперимента, крыс - спустя 3 месяца. Кролики выводились из опыта через 16-17 недель после интоксикации их дитизоном так, как было указано в вышеназванном нашем сообщении. Энуклеированные глаза всех животных заключались в гисторезин и раскладывались на срезы толщиной 5 мкм, которые окрашивались гематоксилин-эозином и просматривались под микроскопом Laboval-4, а при необходимости фотографировались на цифровую фотокамеру. Всего для сравнительного гистологического сопоставления состояния сетчатой и сосудистой оболочек глаз животоных

(C) Э. В. Мальцев, А. В. Зборовская, А. Э. Дорохова, 2012 